\title{
Gas dynamic analysis of the performance of diffuser augmented wind turbine
}

\author{
M T S BADAWY AND M E ALY \\ Mechanical Engineering Department, National Research Center, Dokki, Cairo, \\ Egypt
}

MS received 10 August 1999; revised 10 July 2000

\begin{abstract}
A diffuser augmented wind turbine (DAWT) is considered an important application of the advanced concepts to improve the attractiveness of wind energy. The present paper aims to find a theoretical demonstration of DAWT by using theoretical analysis, mathematical models, assumptions, estimations and maximization of power coefficients and augmentation ratios, in addition to computer programs for calculations and drawings. The final results show that the maximum power coefficient $\left(C p d_{0}\right)$ and augmentation ratio $\left(R_{b}\right)-$ relative to Betz - are directly proportional to pressure recovery factor $(\mathrm{Cr})$, turbine factor $(\mathrm{Ct})$, and maximum velocity ratio $(\mathrm{No})$, but inversely proportional to overall recovery factor $\left(C_{0}\right)$ of diffuser. The power coefficient $\left(C p d_{0}\right)$ of DAWT reaches 1.5 at $C_{0} \cong-0.5, N o \cong 1.0$ and $C r \cong 0.5$, but the augmentation ratio $\left(R_{b}\right)$ reaches 6.0 at $C_{0} \cong-0.5, C r \cong 0.9$, and reaches 7.0 at $N o \cong 1.0$ and $C t \cong 1.0$, which gives a good application for DAWT systems.
\end{abstract}

Keywords. Diffuser flow; diffuser augmented wind turbine; theoretical demonstration; design and performance.

\section{Introduction}

Enclosing a wind turbine by a diffuser reduces the pressure behind the turbine, thus enabling the drawing of more air for flow through the rotor, due to entrance velocity increase. Maximum power rating - for a given blade technology - can be extended substantially by installing a wind rotor at the entrance of a diffuser. The optimal performance of a wind turbine system has been studied (Badawy \& Abd Raboo 1995; Mohamed \& Badawy 1997), whereof the optimal power coefficients can be realized by the use of suitable pitch and twist angles in addition to design parameters such as tip speed ratio with minimum losses $(C p \cong 0.435)$. Gilbert et al (1977) made an experimental program guided by analytical models of various aspects of DAWT flow, where the power coefficient is 2.67 for a local turbine disk coefficient of 0.257 . Forman et al (1976) carried out a general study on the

A list of symbols is given at the end of the paper 
performance of DAWT system, whereby a diffuser area ratio of 3 gives maximum augmentation. Forman \& Gilbert (1979) and Gilbert \& Forman (1978) carried out further investigations of DAWT and experimental demonstration for increasing augmentation. Turbomachinery diffuser design technology and review of diffuser analysis was studied by Japikse (1984), Mayer \& Kneeling (1992) and Johnston (1998). Finally the unified integral method has been demonstrated to produce results which are equal to or better than the performance parameters in terms of accuracy. It is obvious from the previous work, that the optimum configuration regarding numbers, positions, pressure recovery and overall factors of diffuser, suitable area ratio and the diffuser efficiency in addition to velocity ratio must be considered to get the optimum performance of a DAWT system.

In the present paper, a theoretical demonstration of DAWT performance has been realized. Modelling and analysis of DAWT system were estimated and improved for determining the power coefficient and augmentation ratio by changing area ratio, diffuser efficiency, velocity ratio, turbine factor, pressure recovery and overall factor in the computer program.

\section{Modelling and analysis}

Analysis of DAWT performance depends on some assumption, such as one-dimensional potential, incompressible and inviscid flow, where the power coefficient (see figure 1) is given by

$$
C p d=\Delta P_{1-2}\left(\frac{3}{2}\right) V_{2} A_{2} /\left[(1 / 2) \rho A_{2} V_{0}^{3}\right]
$$

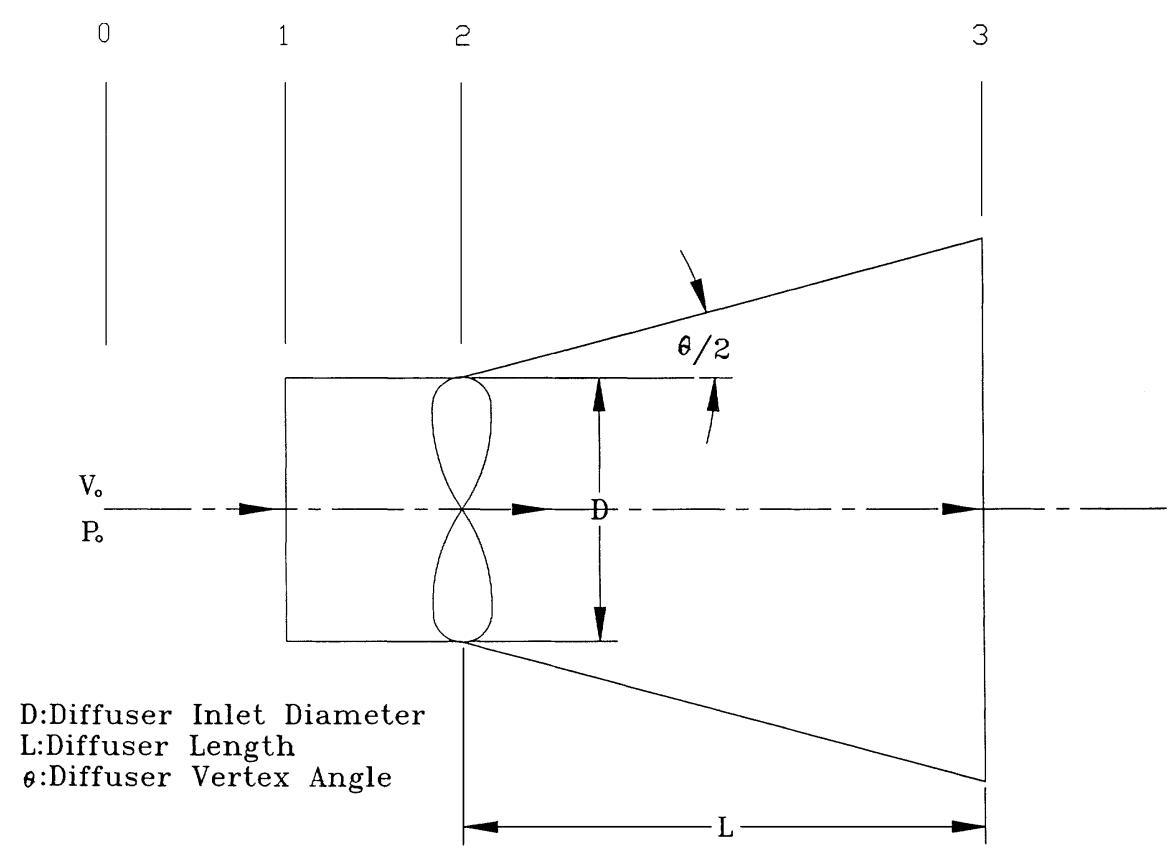

Figure 1. Layout of diffuser augmented wind turbine (DAWT). 
By using of some mathematical operations, we get

$$
\Delta P_{1-2} / \frac{1}{2} \rho V_{0}^{2}=\left(\Delta P_{0-3}-\Delta P_{2-3}\right) / \frac{1}{2} \rho V_{0}^{2}=(1-C o)-N^{2}(1-C r) .
$$

Substituting (2) into (1), the power coefficient of DAWT is

$$
C p d=(3 / 2) N\left[(1-C o)-N^{2}(1-C r)\right]=(3 / 2) N\left[C t+\left(1-N^{2}\right)\right],
$$

where

$$
\begin{aligned}
C r & =\left(P_{3}-P_{2}\right) / \frac{1}{2} \rho V_{2}^{2}=\eta\left(1-m^{2}\right), \quad N=V_{2} / V_{0}, \\
\eta & =\left(P_{3}-P_{2}\right) / \frac{1}{2} \rho\left(V_{2}^{2}-V_{3}^{2}\right), \quad m=A_{2} / A_{3}=\left(1+\left(2 L / D_{2}\right) \tan (\theta / 2)\right)^{-2}, \\
C o & =\left(P_{3}-P_{0}\right) / \frac{1}{2} \rho V_{0}^{2}, \quad C t=\left(P_{0}-P_{2}\right) / \frac{1}{2} \rho V_{0}^{2} .
\end{aligned}
$$

The relation between $C r, C o$ and $C t$ is given by

$$
C t+C o=N^{2} \times C r .
$$

The maximum power coefficient of DAWT (at $\partial C p d / \partial N \approx 0$ ) is given by

$$
C p d_{0}=N_{0}(1-C o)=N_{0}(1+3 C t),
$$

where

$$
N o=[(1+C t) / 3]^{1 / 2}=[(1-C o) / 3(1-C r)]^{1 / 2} \text {. }
$$

The augmentation ratio relative to the Betz limit $\left(R_{b}\right)$ is given by

$$
R_{b}=C p d_{0} / C p_{\text {Betz }}=(27 / 16) C p d_{0}
$$

\section{Computations and algorithm}

From the above modelling and analysis of DAWT performance, it is clear that the power output can be increased significantly by satisfying the following parameters.

(a) Maximum area ratio $(m)$, due to optimum $L / D$ and suitable vertex angle $(\theta)$ of diffuser to get optimum $\mathrm{Cr}$;

(b) optimum diffuser efficiency $(\eta)$ to find optimum $\mathrm{Cr}$;

(c) relation of $\mathrm{Cr}$ for optimum $\mathrm{Ct}$ and $\mathrm{Co}$;

(d) effect of area ratio $(m)$ on $C p d$ at $N, C o$ and $\eta$;

(e) optimum speed ratio $(N)$ for optimum $C p d$;

(f) maximum and suitable pressure recovery factor $(\mathrm{Cr})$;

(g) maximum overall factor $(\mathrm{Co})$ for optimum $\mathrm{Cpd}$;

(h) optimum and suitable turbine load factor $(C t)$.

The algorithm of the determination and computer program is as follows.

(i) Calculating the area ratio $(m)$ from $L, D, \theta$;

(ii) calculating the pressure recovery factor $(\mathrm{Cr})$ from $m, \eta$;

(iii) calculating $\mathrm{Cr}$ from $\mathrm{Ct}, \mathrm{Co}$ and $\mathrm{N}$;

(iv) calculating $C p d$ from $m, C o, N$ and $\eta$; 




Figure 2. Effect of $L / D$ and $\theta$ on the area ratio $(m)$ of diffuser. $\theta=0(\bullet), 5(\boldsymbol{\square}), 10$ $(\boldsymbol{\Delta}), 15(\times), 20(*), 25(\bullet), 30(+)$.

(v) calculating the power coefficient ( $C p d$ ) from $\mathrm{Cr}, \mathrm{Co}, \mathrm{Ct}$, and $\mathrm{N}$ (at different values);

(vi) calculating the maximum velocity ratio (No) from $\mathrm{Co}, \mathrm{Cr}$, and $\mathrm{Ct}$;

(vii) calculating the maximum power coefficient $\left(\mathrm{Cpd}_{0}\right)$ from $\mathrm{No}, \mathrm{Cr}, \mathrm{Co}$ and $\mathrm{Ct}$;

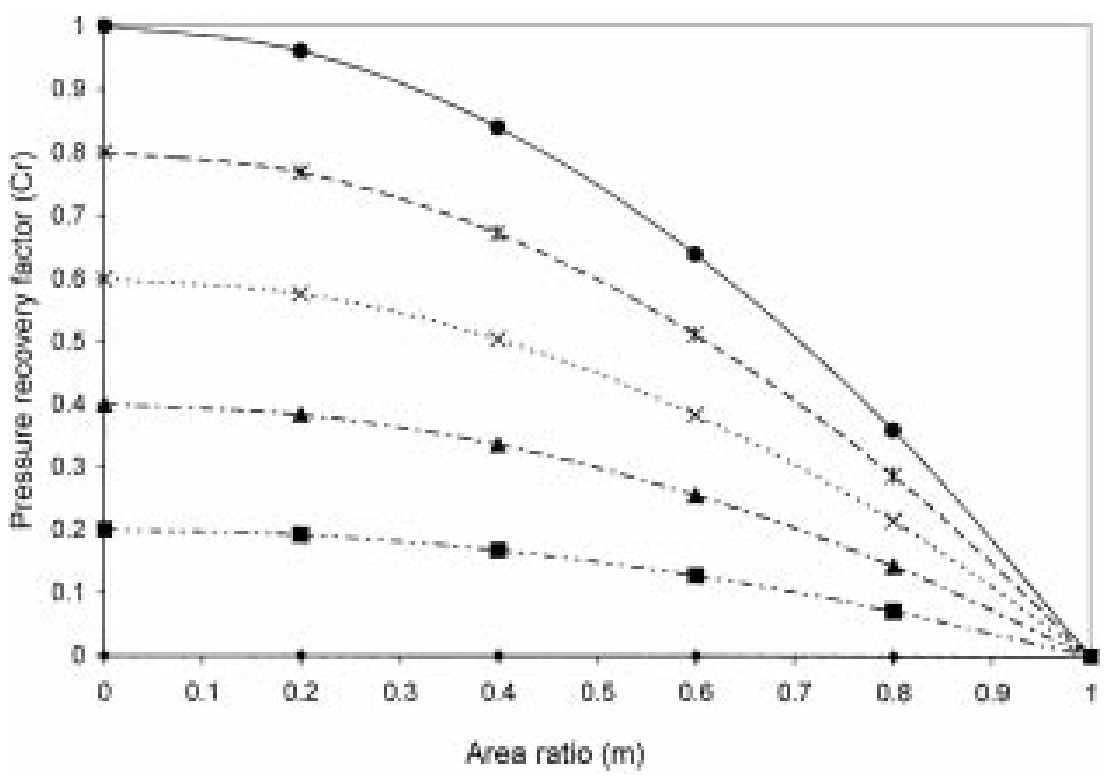

Figure 3. Effect of $m$ and $\eta$ on the pressure recovery factor $(\mathrm{Cr})$ of DAWT. $\eta=0(\diamond)$, $0.2(\square), 0.4(\mathbf{\Delta}), 0.6(\times), 0.8(*), 1.0(\bullet)$. 


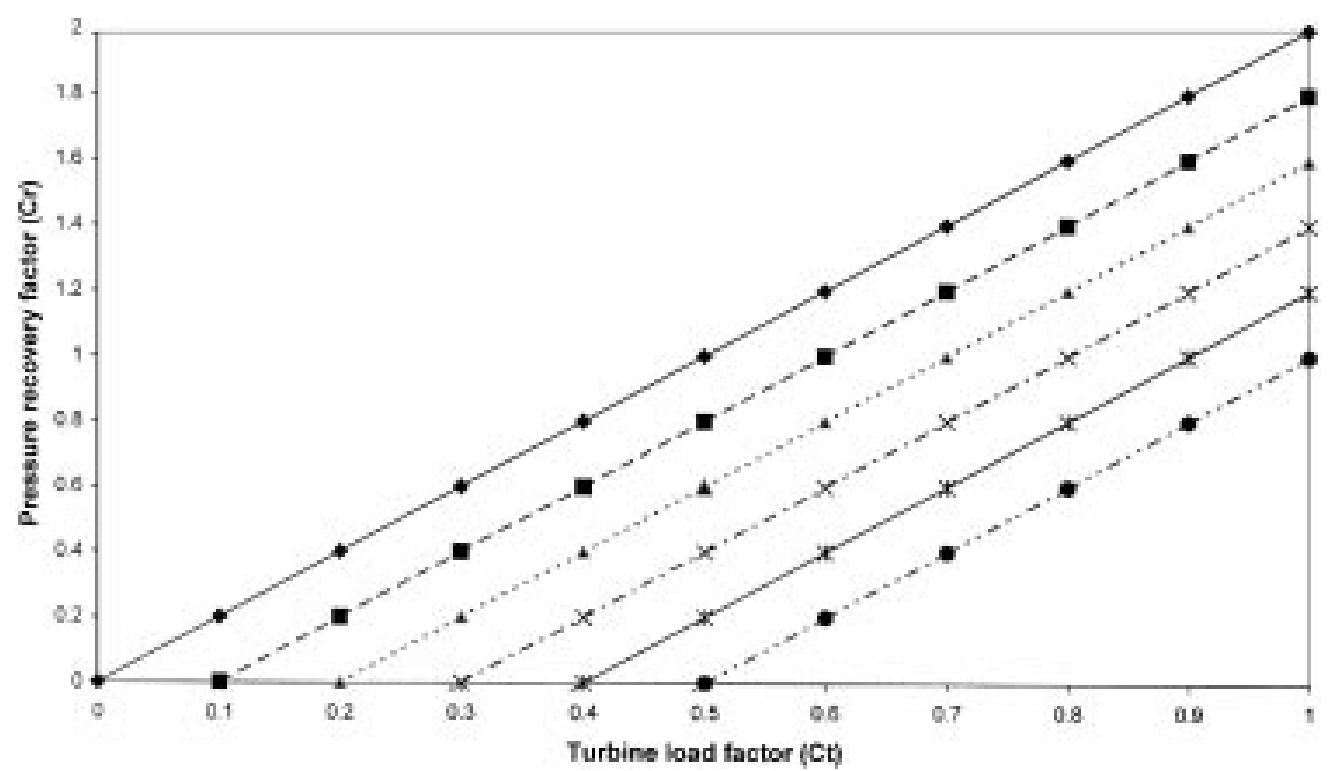

Figure 4. The effect of turbine load factor $(C t)$ and overall recovery factor $(C o)$ on the pressure recovery factor $(\mathrm{Cr})$ of DAWT at $N=0.5$. $C o=0(\bullet),-0.1(\boldsymbol{\square}),-0.2(\boldsymbol{\Delta})$, $-0.3(\times),-0.4(*),-0.5(\bullet)$.

(viii) calculating the augmentation ratio $\left(R_{b}\right)$ from $C p d_{0}, C p_{(\text {Betz })}, C o, C r, C t$, and $N o$;

(ix) plotting these relations to find the optimal power coefficient $\left(C p d_{0}\right)$ and the augmentation ratio $\left(R_{b}\right)$ for DAWT system with $\mathrm{Cr}, \mathrm{Co}, \mathrm{Ct}$, and $\mathrm{No}$ and so on.

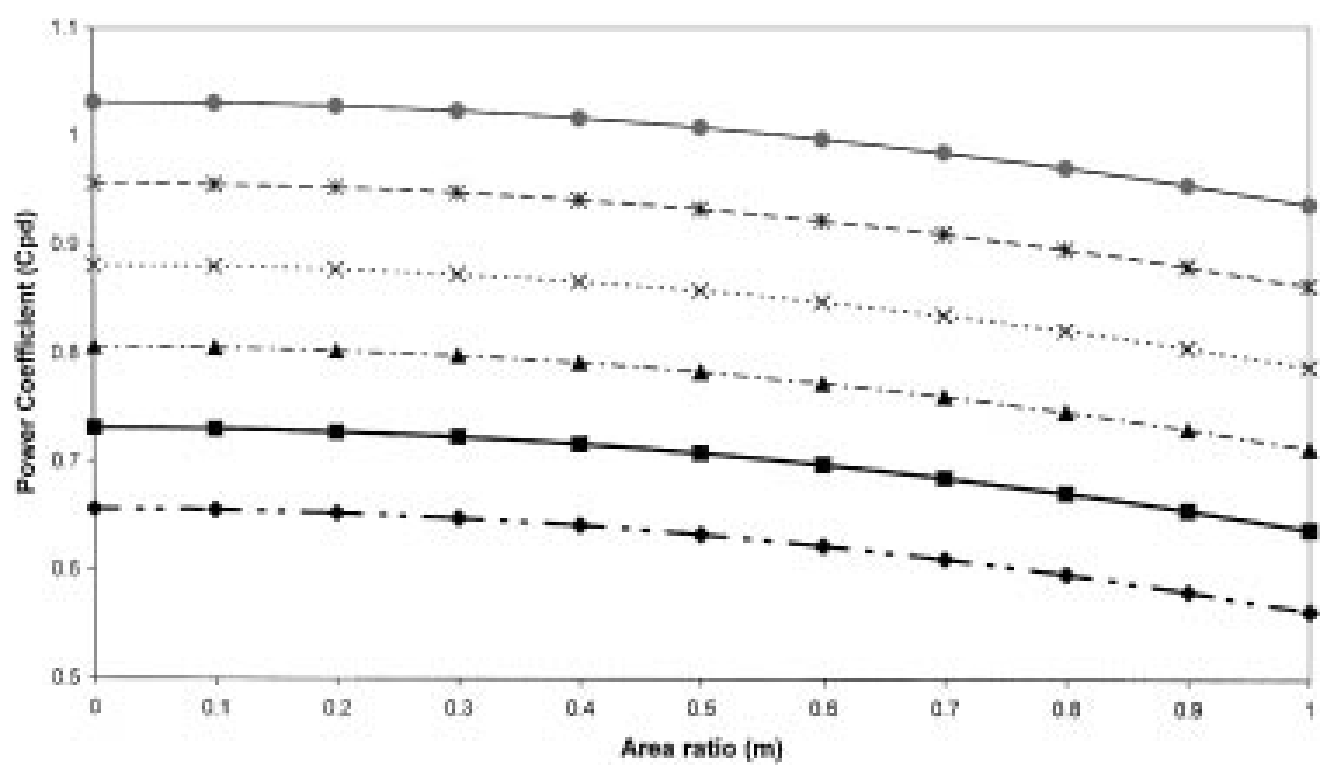

Figure 5. Effect of area ratio $(m)$ on the power coefficient $(C p d)$ of DAWT at $N=0.5$ and $\eta=0.5$. Co $=0(\diamond),-0.1(\boldsymbol{\square}),-0.2(\boldsymbol{\Delta}),-0.3(\times),-0.4(*),-0.5(\bullet)$. 


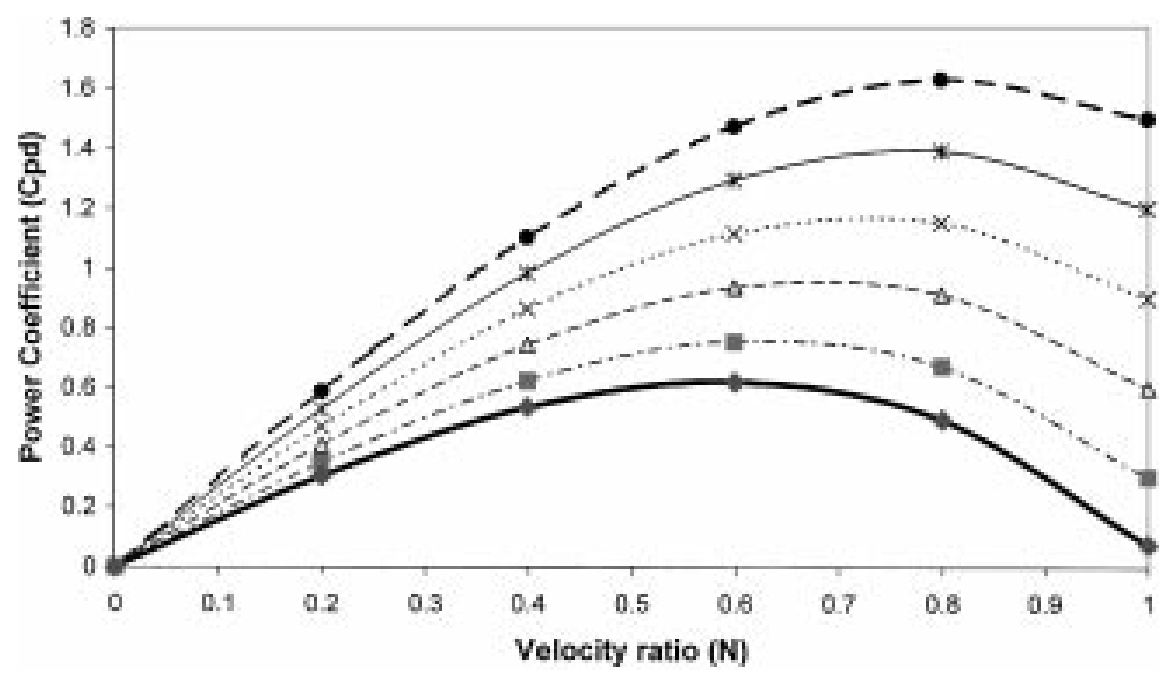

Figure 6. Effect of $N$ and $C t$ on the power coefficient ( $C p d)$ of DAWT. $C t=0.05(\diamond)$, $0.2(\boldsymbol{\square}), 0.4(\triangle), 0.6(\times), 0.8(*), 1.0(\bullet)$.

\section{Results and discussions}

The relation between area ratio $(m), L / D$, and $\theta$ of diffuser is shown in figure 2 , where the area ratio is inversely proportional to $L / D$ and $\theta$. The effect of area ratio $(m)$ and diffuser efficiency $(\eta)$ on the pressure recovery factor is shown in figure 3, where $C r$ is directly proportional to $\eta$, but inversely to $(m)$, for good choice of suitable $C r$ for optimum power coefficient of DAWT system.

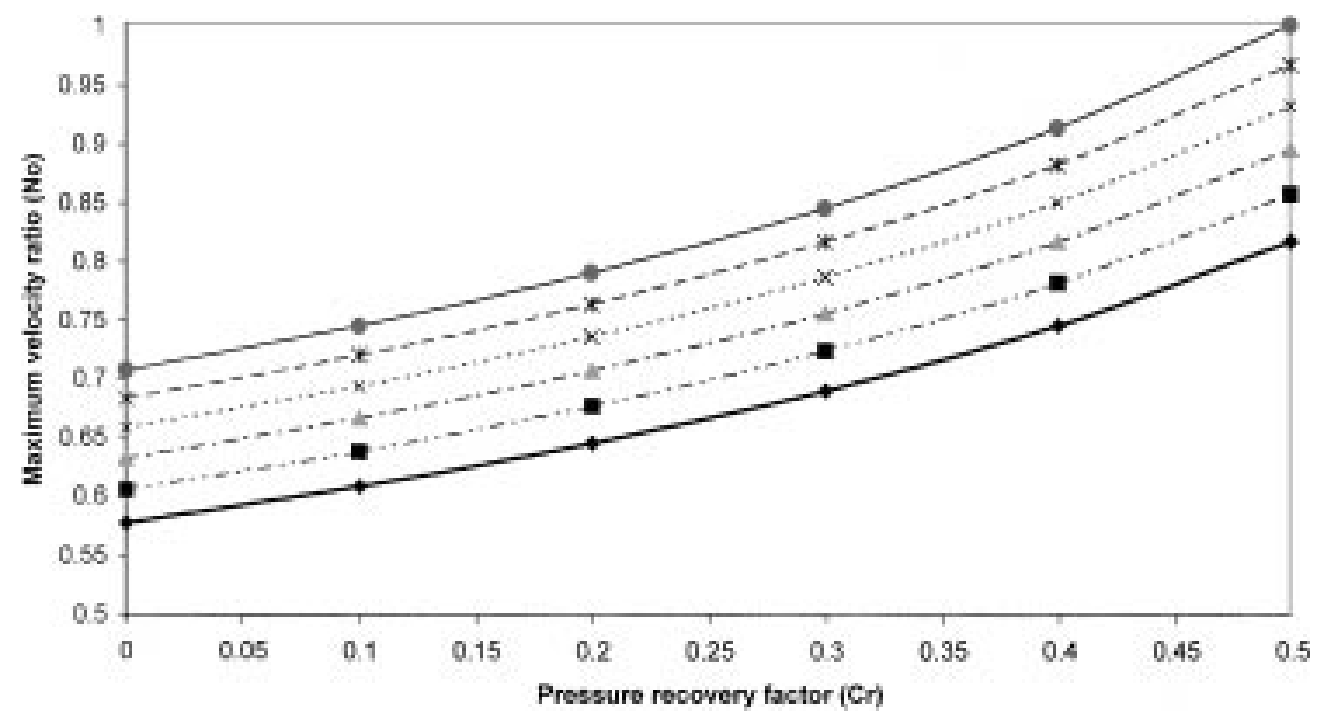

Figure 7. Effect of $\mathrm{Cr}$ and $\mathrm{Co}$ on the maximum velocity ratio (No) of DAWT. Co $=0$ $(\bullet),-0.1(\boldsymbol{\square}), 0.2(\boldsymbol{\Delta}), 0.3(\times), 0.4(*), 0.5(\bullet)$. 


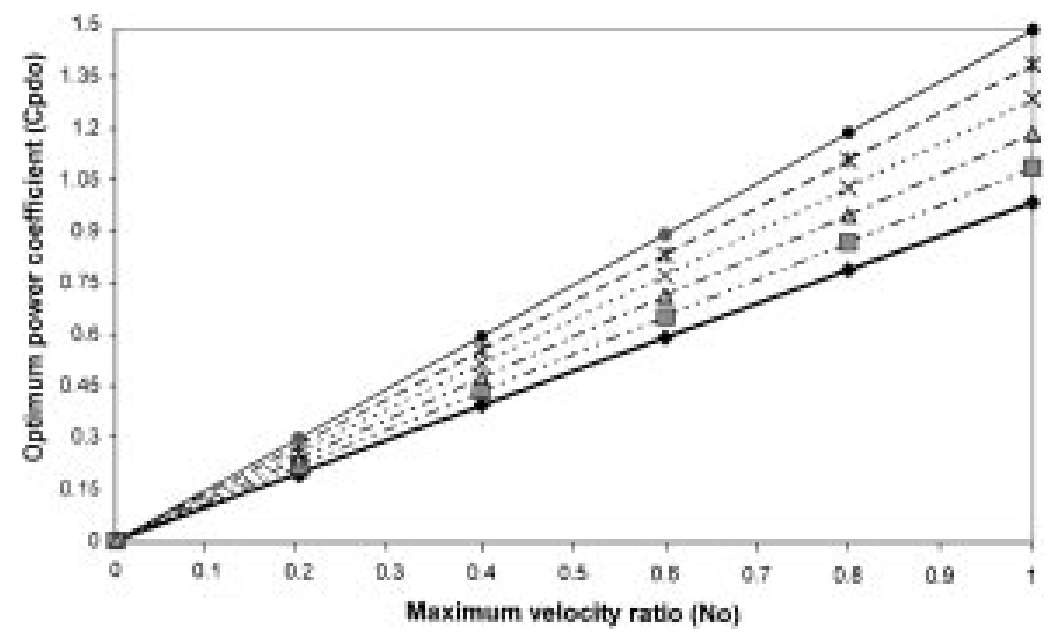

Figure 8. Effect of $N o$ and $C o$ on the optimum power coefficient (Cpdo) of DAWT. Co $=0(\bullet),-0.1(\boldsymbol{\square}),-0.2(\triangle), 0.3(\times), 0.4(*), 0.5(\bullet)$.

The relation between turbine load factor $(C t)$, overall recovery factor $(C o)$ and the pressure recovery factor $(\mathrm{Cr})$ at $N=0.5$ is directly proportional and is shown in figure 4 . The power coefficient $(C p d)$ decreases with the increase of diffuser area ratio $(m)$ at different values of $C o, N=0.5, \eta=0.5$ as shown in figure 5 .

The relation between power coefficient $(C p d)$ and $N, C t$ is shown in figure 6 which shows it is directly proportional to $N$, and $C t$ to a maximum value and then decreases, the optimum value increasing with $N$ and $C t$. The effects of $\mathrm{Cr}, \mathrm{Co}$ and $\mathrm{No}$ on the optimum

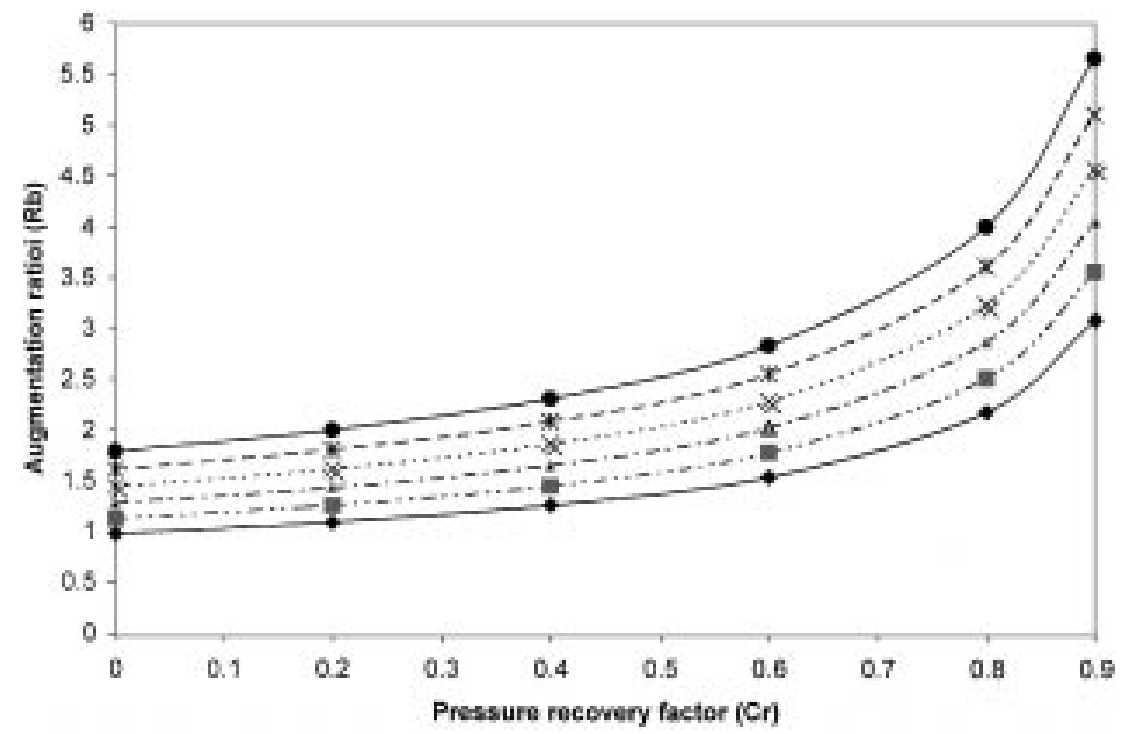

Figure 9. Effect of $C r$ and $C o$ on the augmentation ratio $(R b)$ of DAWT. $C o=0(\diamond)$, $0.1(\boldsymbol{\square}), 0.2(\boldsymbol{\Delta}), 0.3(\times), 0.4(*), 0.5(\bullet)$. 


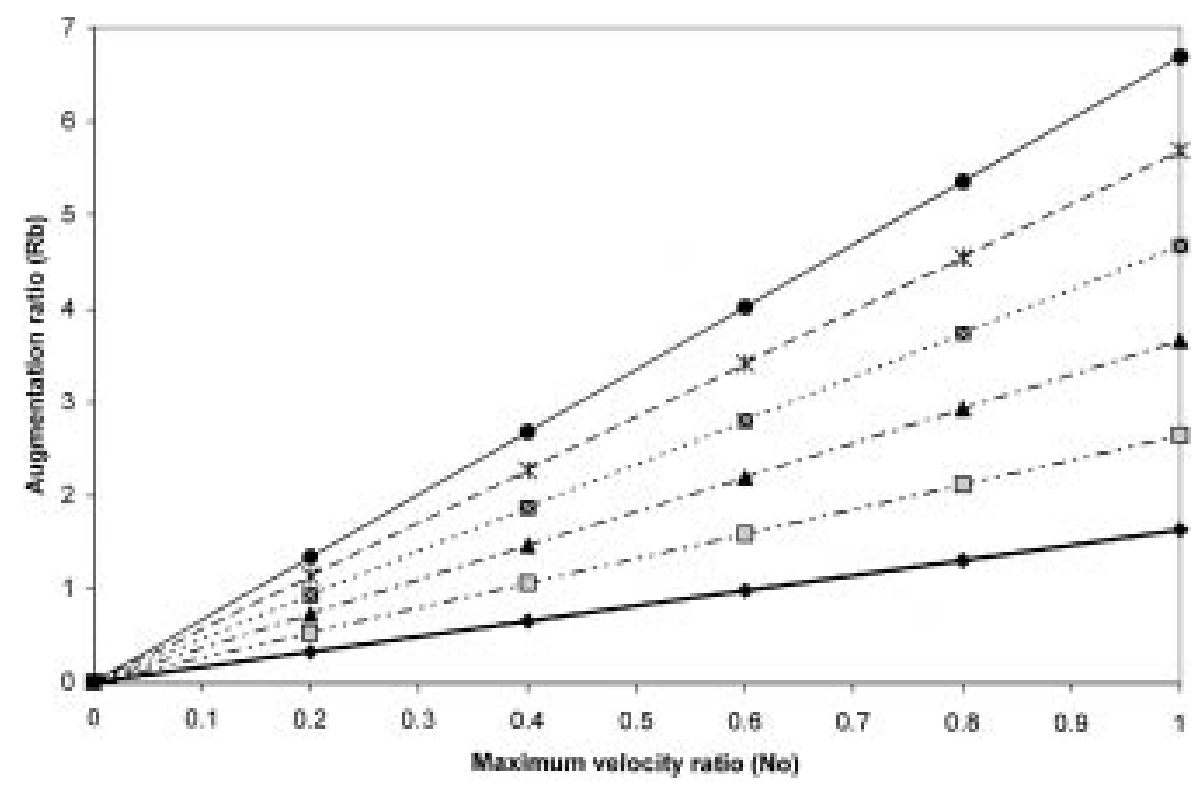

Figure 10. Effect of $N o$ and $C t$ on the augmentation ratio $(R b)$ of DAWT. $C t=0(\diamond)$, $0.2(\boldsymbol{\square}), 0.4(\triangle), 0.6(\times), 0.8(*), 0.1(\bullet)$.

power coefficient $\left(C p d_{0}\right)$ are shown in figures 7 and 8 . It is clear that $C p d_{0}$ is directly proportional to $\mathrm{No}$ and $\mathrm{Co}$, it has a value of 1.5 at $\mathrm{No} \approx 1, \mathrm{Co} \approx-0.5$ and $\mathrm{Cr} \approx 0.5$.

The effects of $C r, C o, C t$ and $N o$ on the augmentation ratio $\left(R_{b}\right)$ are shown in figures 9 and 10 . One can see that $R_{b}$ is directly proportional to $\mathrm{Cr}, \mathrm{Co}$ and $\mathrm{No}$, where the optimum value of $\approx 6$ for $R_{b}$ at $C r \approx 0.9, C o \approx-0.5, N o \approx 1.0$ and $C t \approx 1.0$.

\section{Conclusions}

The conclusions of this paper are as follows.

(1) The power coefficient of DAWT ( $C p d$ ) is directly proportional to $C r, C o, C t, N$ and $\eta$, but inversely proportional to $m$, where suitable choice must be made to get optimal power.

(2) Maximum power coefficient $\left(C p d_{0}\right)$ of DAWT is directly proportional to $\mathrm{Cr}, \mathrm{Co}, \mathrm{Ct}$ and $\mathrm{No}$, and reaches a value of 1.5 at $\mathrm{Co} \approx-0.5, \mathrm{Cr} \approx 0.5, \mathrm{Ct} \approx 1.0$ and $\mathrm{No} \approx 1.0$.

(3) Augmentation ratio relative to Betz $\left(R_{b}\right)$ is directly proportional to $\mathrm{Cr}, \mathrm{Co}, \mathrm{Ct}$ and $\mathrm{No}$, and reaches a value of 6 at $C t \approx 1.0, N o \approx 1.0, C r \approx 0.9$ and $C o \approx-0.5$.

(4) By these analyses and demonstrations, the DAWT system is considered to be a good application to get more power with suitable choice of $m, N, C r, C t, C o$ and $\mathrm{No}$.

\section{List of symbols}

A cross-sectional area at any section $\left(\mathrm{m}^{2}\right)$;

Co overall recovery factor;

Cpd power coefficient of DAWT;

$C p d_{0} \quad$ optimum power coefficient of DAWT; 
$\mathrm{Cr}$ pressure recovery factor;

$C t \quad$ turbine load factor;

$M \quad$ area ratio of diffuser;

$N, N o$ velocity ratio, maximum velocity ratio respectively;

$P \quad$ pressure at any section $\left(\mathrm{N} / \mathrm{m}^{2}\right)$;

$\Delta P \quad$ total pressure difference $\left(\mathrm{N} / \mathrm{m}^{2}\right)$;

$V \quad$ flow velocity $(\mathrm{m} / \mathrm{s})$

$V_{0} \quad$ free stream velocity $(\mathrm{m} / \mathrm{s})$;

$\rho \quad$ air density $\left(\mathrm{kg} / \mathrm{m}^{3}\right)$;

$\eta \quad$ diffuser efficiency.

\section{References}

Badawy M T S, Abd-Raboo M F 1995a Some investigations on the performance of wind turbine blades at different airofoil sections. J. Eng. Res., El-Mataria Eng. Faculty 46: 1-11

Badawy M T S, Abd-Raboo M F 1995b The effect of shear flow on the performance of horizontal axis wind turbines. J. Eng. Res., El-Mataria Eng. Faculty 46: 28-40

Forman K M, Gilbert B L 1979 Further investigations of diffuser augmented wind turbines (New York: Gruman Aerosp. Corp.) vol. 1, pp 714-720

Forman K M, Gilbert B L, Oman R A 1976 Diffuser augmentation wind turbines (New York: Gruman Aerosp. Corp.) vol. 7

Gilbert B L, Forman K M 1978 Experimental demonstration of the diffuser augmented wind turbine concept. Soc. Autom. Eng. 3: 2092-2093

Gilbert B L, Oman R A, Forman K M 1977 Fluid dynamics of diffuser augmented wind turbines. Proceedings 12th Int. Society Energy Conversion, Eng. Conference, vol. 2, pp 412-422

Japikse D 1984 Turbomachinery diffuser design technology. DTS-1, Concepts, ETI, Inc., Box 643, Norwish, VT 05055

Johnston J P 1998 Review: Diffuser design and performance analysis by a unified integral method. Trans. ASME 3: 120-125

Mayer D W, Kneeling W 1992 Evaluation of two-flow analysis for subsonic diffuser design. 30th Aerospace Society Meeting, Dena, NV, AIAA Paper 92-0273

Mohamed F A, Badawy M T S 1997 The optimal characteristics of a horizontal axis wind turbine electric generator system. Florence World Energy Symposium, Italy, pp 717-732 